\title{
Tiagabine Synergistically Interacts with Gabapentin in the Electroconvulsive Threshold Test in Mice
}

\author{
Jarogniew J Łuszczki ${ }^{1,5}$, Mariusz Świąder², Jolanta Parada-Turska ${ }^{3}$ and Stanisław J Czuczwar*,1,4 \\ 'Department of Pathophysiology, Medical University, Lublin, Poland; ²Department of Pharmacology and Toxicology, Medical University, Lublin, \\ Poland; ${ }^{3}$ Department of Rheumatology, Medical University, Lublin, Poland; ${ }^{4}$ Isotope Laboratory, Institute of Agricultural Medicine, Lublin, Poland
}

\begin{abstract}
Polytherapy, based on the rational combining of antiepileptic drugs (AEDs), is required for patients with drug-resistant epilepsy. In such cases, the combinations of AEDs usually offer a significant enhancement of their protective effects against seizures. There has appeared a hypothesis that combining two AEDs, influencing the same neurotransmitter system, results in the potentialization of their anticonvulsant effects. For corroborating this hypothesis, a pharmacological character of interaction between tiagabine (TGB) and gabapentin (GBP) - two novel AEDs affecting the GABA-ergic system, in the maximal electroshock seizure threshold (MEST)-test in mice was evaluated. TGB at the dose of $4 \mathrm{mg} / \mathrm{kg}$ and GBP at $75 \mathrm{mg} / \mathrm{kg}$ significantly raised the electroconvulsive threshold. Further, using the isobolographic calculations, TGB was coadministered with GBP at three fixed-ratios $(1: 3,1: 1$, and $3: 1)$ of their respective protective drug doses. All examined combinations of TGB with GBP exerted supra-additive (synergistic) interactions against MEST-induced seizures in mice. The interaction index, describing the strength and magnitude of interaction, ranged between 0.25 and 0.50 indicating supraadditivity. Adverse (neurotoxic) effects were evaluated in the chimney (motor performance) and the step-through, light-dark passive avoidance (long-term memory) tests in mice. The examined combinations of TGB with GBP did not affect the motor coordination, except for the fixed-ratio of $I: I$, at which significant impairment of motor performance was observed. Moreover, all combinations selectively impaired the acquisition of the task in the passive avoidance test, having no impact on consolidation and retrieval in the longterm memory test. The pain threshold test revealed that the observed disturbances in the passive avoidance testing resulted presumably from the antinociceptive activity of these AEDs in combinations. After lengthening the exposing time to the direct current stimulus in the passive avoidance test from 2 to $6 \mathrm{~s}$, the acquisition of the task, in animals receiving the combinations of TGB and GBP was not impaired. Neither the plasma, nor brain concentrations of GBP were affected by TGB application, so pharmacokinetic events that might negatively influence the observed effects are not probable. Results of this study clearly indicate that the activation of the same neurotransmitter system (GABA-ergic) leads to a synergistic interaction. The pain threshold test is a very good paradigm for screening the antinociceptive properties of AEDs, which may disturb the long-term memory testing in animals. Combinations of TGB with GBP (very promising from a preclinical point of view) should be clinically verified for elaborating the most effective treatment regimen in patients with intractable seizures.
\end{abstract}

Neuropsychopharmacology (2003) 28, | 817-1830, advance online publication, 16 July 2003; doi: | 0.1038/sj.npp. 1300243

Keywords: tiagabine; gabapentin; isobolographic analysis; electroconvulsive threshold; pain threshold; drug interactions; seizures

\section{INTRODUCTION}

Although monotherapy with an antiepileptic drug (AED) has been established as a standard treatment of choice for epilepsy (Reynolds and Shorvon, 1981), there are a number

*Correspondence: Professor SJ Czuczwar, Department of Pathophysiology, Medical University, Jaczewskiego 8, 20-090 Lublin, Poland, Tel: +48 8I 74258 37, Fax: +48 81 74258 28,

E-mail: czuczwar@galen.imw.lublin.pl

${ }^{5}$ Recipient of the Fellowship for Young Researchers from the Foundation for Polish Science.

Received 09 December 2002; revised 05 May 2003; accepted 08 May 2003

Online publication: 23 May 2003 at http://www.acnp.org/citations/ Npp5222453/default.pdf of patients, who do not adequately respond to the usually applied first prescribed drug (Krämer, 1997). In spite of progress in the understanding of pathophysiological processes underlying the epileptogenesis and seizure propagation (Olsen and Avoli, 1997), as well as the profound knowledge of possible mechanisms of action of conventional and novel AEDs (Czuczwar and Patsalos, 2001; Macdonald and Greenfield, 1997), there are still approximately $30 \%$ of patients being refractory to the applied standard AED treatment regimen (Brodie, 2001). In such cases, an alternative monotherapy may control the seizures; however, a complete suppression of convulsive attacks can be seldom achieved with an AED, even if it is administered at the maximally prescribed dose (Krämer, 1997). In case of intractable seizures, the treatment of choice is the addition 
of a second AED, usually a novel one, to the established conventional monotherapy, which is expected to protect the patients against convulsive episodes (Perucca, 1995). Therefore, the combined treatment regimen with AEDs, based on theoretical assumptions and experimental guidelines, seems to be the best rational issue for these patients (Deckers et al, 2000). So far, polytherapy providing a reduction of seizures is of some clinical interests and advantageous for the patients with refractory seizures. Nowadays, an adjuvant therapy with a novel AED seems to be the most effective treatment with regard to the reduction of seizure attacks in these patients (Krämer, 1997). The benefits of combined anticonvulsant therapy, in particular, result in a drug-dose reduction, diminution of quantity and/or severity of deleterious side effects exerted by the drugs applied at effective but maximally tolerated doses in monotherapy, and also results in the possibility of controlling diverse types of seizures (Perucca, 1995; Genton and Roger, 1997). On the other hand, in case of polytherapy, some unpredicted interactions between applied AEDs, manifesting drug toxicity, may also occur which often complicate the treatment of epilepsy (Perucca, 1997).

From a clinical point of view, only rational polytherapy, based on animal experiments and theoretical presumptions, is expected to be applied in patients with intractable seizures (Czuczwar, 1998; Perucca, 1995; Schmidt, 1996; Deckers et al, 2000). The convincing evidence suggests that drug combinations with completely diverse mechanisms of action may be profitable by enlarging a spectrum of activity against various types of convulsions and concomitantly by diminishing the maximally tolerated dose of antiepileptics applied in monotherapy (Perucca, 1995). However, it seems interesting whether coadministration of two AEDs influencing the GABA-ergic system (in particular, when both drugs cause the elevation of GABA concentration into synaptic clefts by diverse mechanisms of action) may intensify and potentiate the protective antiseizure effects. Comparatively, little research has been carried out on interaction effects of compounds influencing the same neurotransmitter system, although the GABA plays an important role in the brain functions (Klitgaard et al, 1993).

Tiagabine $[R(-)-N$-(4,4-di(3-methyl-thien-2-yl)-but-3enyl)nipecotic acid, hydrochloride; TGB], a novel AED lately introduced into the therapy of partial seizures in humans, is a potent GABA uptake inhibitor into neurons and glia, which by blocking the GABA transporter 1 (GAT1) in mice, significantly prolongs the duration of GABArelated inhibitory synaptic potentials (Czuczwar and Patsalos, 2001; Nielsen et al, 1991). The net effect of the increment in synaptic GABA concentration is evidently related to the reduction of seizure frequency in patients with partial-onset seizures (Richens et al, 1995; Sachdeo et al, 1997; Uthman et al, 1998). Tiagabine is efficacious either as an adjuvant drug in adult patients and children with partial seizures with/without secondary generalization (Ben-Menachem, 1995; Pellock, 2001) or the drug, applied in monotherapy (Schachter, 1995). Moreover, it is used in the add-on therapy of refractory seizures (Biraben et al, 2001; Kalviainen et al, 1998).

Gabapentin [1-(aminomethyl)-cyclohexane acetic acid; GBP], possesses many diverse mechanisms of action, among them, the inhibition of $\mathrm{Ca}^{2+}$ voltage-gated channels, through interaction with the $\alpha_{2} \delta$ subunit, seems to be the most important (Gee et al, 1996). Primarily, gabapentin (GBP) was synthesized as a GABA-analog that, in contrast to $\mathrm{GABA}$, readily penetrated through the blood-brain barrier (Ojemann et al, 1988). Despite its chemical structure (similar to GABA), GBP does not alter radioligand binding at $\mathrm{GABA}_{\mathrm{A}}$ or $\mathrm{GABA}_{\mathrm{B}}$ receptors (Rogawski and Porter, 1990). At therapeutically relevant concentrations, GBP does not interact with receptors for GABA, glutamate, glycine, or dopamine (Taylor et al, 1998) and does not affect voltagegated $\mathrm{Na}^{+}$channels (Stefani et al, 2001). GBP interacts with several enzymes of the inextricably linked metabolic pathways of GABA (activates glutamate decarboxylase (GAD) and weakly inhibits GABA transaminase (GABA-T); increasing GABA concentration) and metabolic pathways of glutamate (slightly activates glutamate dehydrogenase (GDH) and potently inhibits branched-chain amino acid aminotransferase (BCAA-T); decreasing glutamate concentration) (Goldlust et al, 1995). GBP competes with transport of branched-chain amino acids (L-leucine, L-valine, Lphenylalanine), therefore, some pharmacologic properties of GBP may arise from changes in cytosolic concentrations of endogenous amino acids in neurons (Taylor et al, 1998). Moreover, GBP increases the conductance of hyperpolarization-activated cation currents $\left(I_{\mathrm{h}}\right)$ contributing to the protection of neurons against excessive synaptic or intrinsic activity, and stabilizing neuronal network within the hippocampus (Surges et al, 2003). After all, GBP is approved as an add-on therapy (Fisher et al, 2001) or monotherapy for partial seizures with/without secondary generalization (Chadwick et al, 1998). Also, GBP is effective in the refractory epilepsy in children (Appleton et al, 1999).

Considering the mechanisms of action of some novel AEDs, we attempted to determine the interaction between TGB and GBP in the maximal electroshock seizure threshold (MEST)-test in mice. In our study, one of the major interests is to predict the drug interactions and denote which one is particularly effective and worth considering for clinical practice.

\section{MATERIALS AND METHODS}

\section{Animals}

The experiments were carried out on male Swiss mice purchased from a licensed dealer, weighing $20-26 \mathrm{~g}$. The animals were kept under standardized laboratory conditions with free access to food (chow pellets) and tap water, and maintained on a natural light-dark cycle. The experimental groups, consisting of 8-20 animals, were chosen by means of a randomized schedule. The electroconvulsive and behavioral tests were performed between 0800 and 1500, and each mouse was used only once. Since the control threshold in mice varies, the control groups were tested on each day parallel to threshold determinations in drugtreated animals (Löscher et al, 1991). The temperature in the animal room and during testing was $21 \pm 1^{\circ} \mathrm{C}$. All experimental procedures described below were approved by the Local Bioethical Committee in Lublin (License No. 161/ $2000 / 123 / 01)$ and $(356 / 2002 / 376 / 02)$. 


\section{Drugs}

The following antiepileptics were used in this study: TGB (GABITRIL - Sanofi Winthrop, Gentilly, France) and GBP (NEURONTIN - Parke-Davis, Freiburg, Germany). Both drugs were suspended in a $1 \%$ solution of Tween-80 (Sigma, St Louis, MO, USA) and administered intraperitoneally (i.p.) in a volume of $10 \mathrm{ml} / \mathrm{kg}$ body weight. The doses of drugs refer to the free drug forms and the drugs were injected TGB $15 \mathrm{~min}$, and GBP $60 \mathrm{~min}$, prior to the tests. The control animals received adequate amounts of vehicle.

\section{MEST-Test}

Electroconvulsions were produced by means of an alternating current $(0.2 \mathrm{~s}$ stimulus duration, $50 \mathrm{~Hz})$ delivered via standard auricular electrodes by a Hugo Sachs generator (Rodent Shocker, Type 221, Freiburg, Germany). The end point was the maximal (tonic) extension of the hind limbs. In the MEST-test, at least four groups of mice consisting of 8-10 animals were subjected to the electroshocks of various intensities, in order to evaluate the threshold for maximal hindlimb extension. Subsequently, an intensity-response curve was calculated according to Litchfield and Wilcoxon (1949) from the percentage of mice showing the hindlimb extension. The electroconvulsive threshold was evaluated as a $\mathrm{CS}_{50}$ value (current strength in $\mathrm{mA}$ ) necessary to induce tonic hindlimb extension in $50 \%$ of the mice tested. The protective effects of TGB and GBP alone or combined were determined as the $\mathrm{CS}_{50}$ values, being significantly higher than the respective $\mathrm{CS}_{50}$ values of control groups. The animal groups were injected with different doses of investigated drugs in order to obtain a significant protection against electroconvulsions.

\section{Analysis of Interactions}

The experimental protocol, for evaluating the character of interactions between TGB and GBP in the MEST-test, was conducted according to the isobolographic method described in detail by Tallarida et al (1997). However, the applied isobolography was substantially modified. Actually, it was composed of two methods: the first one-simply evaluated the threshold for the maximal hindlimb extension in mice, and the second one-was based on the isobolographic transformation of data obtained directly from the MEST-test.

Isobolographic analysis usually determines the equieffective drug doses for properly classifying interactions as: synergistic, antagonistic, or additive. The protective activity of TGB and GBP alone or in combinations was expressed as a significant increase of the electroconvulsive threshold. In the present study, a significant elevation (at $P<0.05$ ) of the current strength, needed to evoke seizures in pretreated animals was established as the final outcome. In other words, the doses of TGB or GBP, which similarly increase the $\mathrm{CS}_{50}$ values (at $P<0.05$ ), were considered as the equieffective ones, and subsequently underwent the isobolographic calculations. Determination of the combined drug doses in mixtures was elaborated in accordance with the standard isobolographic method by using three fixed- ratio combinations as follows: $1: 3,1: 1$, and $3: 1$. Isobolographic calculations of the additive drug doses in mixtures were thoroughly presented in our previous study (Luszczki et al, 2003a). Subsequently, the mixtures of TGB with GBP (the effect of which was theoretically presumed as the additive one) were given to animals, and again the electroconvulsive threshold was experimentally determined, and compared with the threshold of vehicle-treated animals (the reference group). Results were statistically analyzed with a computer program based upon the original logprobit transformation according to Litchfield and Wilcoxon (1949). The combination of TGB with GBP at the fixed-ratio of $3: 1$ was a simple transcription of the drug proportions in the mixture composed of TGB $(3 \mathrm{mg} / \mathrm{kg})$ and GBP $(18.75 \mathrm{mg} / \mathrm{kg})$. In this drug mixture, TGB prevails over GBP in terms of its pharmacological activity against electroconvulsions, but it does not prevail quantitatively in the mixture. The drug mixture for the combination of $1: 1$ consisted of TGB $(2 \mathrm{mg} / \mathrm{kg})$ and GBP $(37.5 \mathrm{mg} / \mathrm{kg})$, where the drugs were combined in equieffective (isoeffective) doses, corresponding to halves of the effective doses of the drugs tested separately in our study. Analogously, the fixed-ratio combination of $1: 3$ was a simple notation for the mixture composed of TGB (1 mg/kg) and GBP $(56.25 \mathrm{mg} /$ $\mathrm{kg})$. All the above-mentioned drug doses for the respective combinations were primarily considered as the additive ones because they were directly calculated from the line of additivity (Tallarida et al, 1997; Luszczki et al, 2003b). It is clear that the final effect of the drug mixture needed to be similar as the drugs were administered separately. Therefore, the experimental $\mathrm{CS}_{50 \mathrm{mix}}$ values were always compared with the respective control $\mathrm{CS}_{50}$ values. $\mathrm{CS}_{50}$ mix corresponds to an experimentally determined current strength, after administration of the mixture of two component drugs in a fixed dose ratio, sufficient for a $50 \%$ convulsive effect. If the actual $\mathrm{CS}_{50 \text { mix }}$ does not differ statistically from the respective control $\mathrm{CS}_{50}$, the effect of the drug in mixture is additive; otherwise if the $\mathrm{CS}_{50 \text { mix }}$ is statistically higher than the control $\mathrm{CS}_{50}$ value, a synergistic interaction occurs. The experimentally obtained drug doses in a mixture, which significantly raised the threshold at $P<0.05 v s$ the control group, were graphically presented on an isobologram to determine approximately the strength and magnitude of the obtained interactions (Tallarida, 2002). The isoboles were drawn by plotting the experimentally determined dose of TGB on $X$-axis and that of GBP on the $Y$-axis. To point the experimental drug-dose mixture on the graph, the doses of both drugs were summed according to the standard isobolographic method (Tallarida, 1992).

It should be stressed that the presented modification of the isobolographic method may be accepted if both AEDs exert the same $(50 \%)$ effect. The reduction of drug doses in mixtures allowed the assessment of the $\mathrm{CS}_{50}$ mix values, which did not statistically differ from that of the respective control groups. However, with this modification it was impossible to denote the $95 \%$ confidence limits or SEM for the drug-dose mixture either for additive or experimental values. Therefore, the interaction index (a quotient of experimental and additive drug-dose mixture) was used as a predicator of synergy, especially if its value did not exceed 0.7 (indicative for synergy-Kerry et al, 1975, Bourgeois, 1986, 1988). 


\section{Chimney Test}

The effects of TGB or GBP alone or in combination upon motor performance were determined in the chimney test, according to Boissier et al (1960). In this test, animals had to climb backwards up a plastic tube $(25 \mathrm{~cm}$ length, $3 \mathrm{~cm}$ inner diameter). Motor impairment was indicated by the inability of the animals to perform the test within $60 \mathrm{~s}$. The experimental groups in this test consisted exceptionally of 20 animals. Results were expressed as a percentage of mice failing to perform this test. The tested doses of TGB or GBP correspond to the doses previously denoted in the MESTtest in mice.

\section{Step-Through Passive Avoidance Task}

The animals were placed in an illuminated box $(10 \times 13 \times 15 \mathrm{~cm})$ connected to a large dark box $(25 \times 20 \times 15 \mathrm{~cm})$ equipped with an electric grid floor. The entrance to the dark box was punished by an electric footshock $(0.6 \mathrm{~mA}$ for $2 \mathrm{~s}$; facilitation of acquisition). The mice who did not enter the dark compartment were excluded from the experiment. On the next day ( $24 \mathrm{~h}$ later), the pretrained animals were put again into the illuminated box and observed up to $180 \mathrm{~s}$. Mice who avoided the dark compartment for $180 \mathrm{~s}$ were considered to remember the task. Time at which mice enter the dark box, was noted and subsequently, the medians with 25 and 75 percentiles were calculated. The step-through, dark-light passive avoidance task gives information about acquisition (learning), consolidation, and retrieval; therefore, may be regarded as a measure of long-term memory (Venault et al, 1986). The influence of AEDs administered alone or in combinations on long-term memory was evaluated in three variants as follows:

(1) Variant A - the drugs were administered on the first day, before the training session (ie TGB-15 min and GBP $-60 \mathrm{~min}$ ). On the next day ( $24 \mathrm{~h}$ later), the mice were challenged with the test and retention was measured.

(2) Variant B - the AEDs were administered immediately after the training session. On the next day, ( $24 \mathrm{~h}$ later) mice were challenged with the task and retention was measured.

(3) Variant $\mathrm{C}$ - the naïve mice (without any treatment) were pretrained on the first day, and the drugs were administered on the next day ( $24 \mathrm{~h}$ later), before retention. The testing session was performed at times scheduled for the MEST-test.

\section{Pain Threshold Test}

The pain threshold was assessed in our study, as a minimal exposing time to an electrical stimulation required for inducing a pain reaction in animals. This test was performed under conditions identical to the experiment testing the step-through passive avoidance task. The animals were placed separately on the grid surface connected with a current generator. Afterwards, each mouse was exposed to a direct current $(0.6 \mathrm{~mA})$, and the time to induce a first pain reaction in animals was measured and expressed in (s) as the latency. For ethical reasons, the animals were exposed to the current impulse up to $14 \mathrm{~s}$. In case the mouse did not express any reactions to the stimulus within $14 \mathrm{~s}$, the test was terminated and the animal was assigned this cutoff latency. It has to be stressed that the first pain reaction was considered as the end point and after displaying some reactions, the animals were immediately set free from the stimulation. To evaluate the latency to pain reaction, testing took place 15 or $60 \mathrm{~min}$ after the i.p. administration of TGB and GBP, respectively. The first pain reaction of animals observed in our study was expressed as: jerks of forelimbs or a whole body with or without squeaking; violent seeking of escape with a tentative attempt at jumping out; wild running. The reaction of control animals to electrical stimulus was instantaneous and the latency did not exceed $2 \mathrm{~s}$. All testing was carried out in unanesthetized mice.

\section{Chromatographic Determination of GBP Plasma and Brain Concentrations}

GBP was analyzed quantitatively in plasma and brains of animals at times scheduled for the MEST-test. The animals were injected GBP alone or a combination of TGB with GBP in respective fixed dose ratios of $1: 3,1: 1$, and $3: 1$. Mice were decapitated and samples of blood of approximately $1 \mathrm{ml}$ were rapidly collected in heparinized Eppendorf tubes. Simultaneously, brains of mice were removed from skulls and placed into the deep freeze at $-80^{\circ} \mathrm{C}$ (Polar 530, Angelantoni, Massa Martana, Italy - sponsored by a KBN Grant No. 6P05D 098 21). Samples of blood were centrifuged at $10000 \mathrm{rpm}$ (Abbott centrifuge, Irving, TX, USA) for $5 \mathrm{~min}$, and plasma samples of $200 \mu \mathrm{l}$ were stocked in the deep freeze. On the next day, the brains were homogenized in an original Abbott buffer (2:1 vol/wt), using the Ultra-Turrax T8 homogenizer (Staufen, Germany). The homogenates were centrifuged at $10000 \mathrm{rpm}$ for $10 \mathrm{~min}$. Plasma and brain homogenate samples of $100 \mu \mathrm{l}$ were added to $200 \mu \mathrm{l}$ of acetonitrile. The samples were mixed and centrifuged at $10000 \mathrm{rpm}$ for $5 \mathrm{~min}$. Then, $50 \mu \mathrm{l}$ of supernatant was mixed with $100 \mu$ of $O$-phthaldialdehyde reagent and derivatized at room temperature for $1 \mathrm{~min}$. Samples of $20 \mu \mathrm{l}$ were then injected into the chromatograph. The chromatograph (HP 1050) was equipped with a fluorescence detector (HP 1046A). For HPLC, a stainlesssteel HP Hypersil ODS column $(200 \times 4.6 \mathrm{~mm})$ was used at an ambient temperature of $22^{\circ} \mathrm{C}$. The mobile phase consisted of acetonitrile: methanol: acetate buffer $(20 \mathrm{mM}$ acetic acid and $250 \mathrm{mM}$ sodium acetate); $285: 320: 395 \mathrm{vol} /$ vol/vol (BAKER HPLC grade). The mobile phase flow rate was $1 \mathrm{ml} / \mathrm{min}$. The amount of GBP was determined by comparing their peak area with the peak area of the external standard (naphthalene). The wave excitation and emission parameters for fluorescent detection of GBP were 340 and $440 \mathrm{~nm}$, respectively. Plasma levels or brain concentrations of GBP were expressed in $\mu \mathrm{g} / \mathrm{ml}$ of plasma or $\mu \mathrm{g} / \mathrm{g}$ of wet brain tissue as means \pm SD of at least eight determinations.

\section{Statistical Analysis}

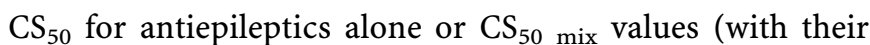
$95 \%$ confidence limits) were calculated and statistically 
analyzed by computer probit analysis according to Litch-

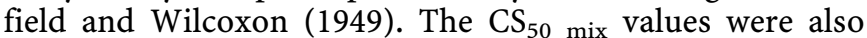
compared with the respective $\mathrm{CS}_{50}$ values of the control groups and were statistically significant at $P<0.05, P<0.01$, or $P<0.001$. Results from the chimney test were analyzed by using Fisher's exact probability test. The Kruskal-Wallis nonparametric ANOVA test followed by post hoc Dunn's test were used for statistical assessment of data in the pain threshold and the step-through, dark-light passive avoidance tasks. Concentrations of GBP alone or combined with TGB, in plasma or brains, were evaluated by means of unpaired Student's $t$-test. Interaction indices for all fixedratio combinations of TGB with GBP $(1: 3,1: 1$, and $3: 1)$, tested in our study, were calculated as follows: total amount of drug doses in experimental mixture/total drug doses theoretically denoted from the line of additivity, both showing a similar effect.

\section{RESULTS}

\section{Effects of TGB and GBP Alone upon the Electroconvulsive Threshold}

TGB at doses of 4 and $6 \mathrm{mg} / \mathrm{kg}$; i.p. $15 \mathrm{~min}$ before the MESTtest, raised the threshold for electroconvulsions from $7.4 \mathrm{~mA}(6.6-8.4)$ to $8.7 \mathrm{~mA}(8.0-9.4)$ and $9.3 \mathrm{~mA}(8.6-$ 10.0), respectively, at $P<0.05$ and $P<0.01$, while TGB at $2 \mathrm{mg} / \mathrm{kg}$ did not significantly influence the electroconvulsive threshold in mice. GBP at doses of 75 and $100 \mathrm{mg} / \mathrm{kg}$ (i.p. $60 \mathrm{~min}$, prior to the test) elevated the threshold from $7.2 \mathrm{~mA}$ $(6.2-8.4)$ to $9.0 \mathrm{~mA}(8.2-9.8)(P<0.05)$ and $9.7 \mathrm{~mA}(8.7-$ 10.9) $(P<0.01)$, respectively, whereas at up to $50 \mathrm{mg} / \mathrm{kg}$, the drug had no significant influence upon the electroconvulsive threshold in mice (results not shown).

\section{Influence of Combinations of TGB with GBP upon the Threshold for Electroconvulsions}

In all fixed-ratio combinations tested, TGB and GBP (at the doses isobolographically presumed as the additive ones) potentiated their own activity, elevating the threshold for electroconvulsions in mice. For the fixed drug-dose combination of $1: 3$, TGB $(0.25 \mathrm{mg} / \mathrm{kg})$ coadministered with GBP $(14.1 \mathrm{mg} / \mathrm{kg})$, enhanced significantly the protection of animals against electroconvulsions at $P<0.05$, whereas the drug doses for the same combination: TGB (1) with GBP (56.25) (theoretically presumed as the additive one), considerably elevated the threshold in comparison with the control group (at $P<0.001)$. TGB $(1.5 \mathrm{mg} / \mathrm{kg}$ ) and GBP $(9.4 \mathrm{mg} / \mathrm{kg})$, for the drug-dose combination of $3: 1$, also modified their own effects upon the threshold for electroconvulsions $(P<0.05)$. Obviously, higher doses of the drugs in combinations exerted more significant increment of the electroconvulsive threshold in mice (Table 1). It should be emphasized that the interaction index for the combination of TGB with GBP, at the fixed-ratio of $1: 3$ was 0.25 , while for the drug-dose combination of $3: 1$, its value was equal to 0.50 . The interaction index for the $1: 1$ combination was 0.38 , indicating that all interactions were supra-additive (synergistic; Table 1; Figure 1).
Table I Interactions Between TGB and GBP in the MEST-Test in Mice

\begin{tabular}{|c|c|c|}
\hline $\mathbf{F}$ & Treatment (mg/kg) & $\mathrm{CS}_{50 \text { mix }}(\mathrm{mA})$ \\
\hline $3: 1$ & $\begin{array}{l}\text { Control } \\
\text { TGB (3)+GBP ( I } 8.75) \\
\text { TGB (1.5)+GBP (9.4) } \\
\text { TGB (I)+GBP (6.3) }\end{array}$ & $\begin{array}{l}7.9(7.1-8.8) \\
10.4(9.5-11.4)^{* * * *} \\
9.4(8.6-10.4)^{*} \\
8.4(7.6-9.4)\end{array}$ \\
\hline $1: 1$ & $\begin{array}{l}\text { Control } \\
\text { TGB (2)+GBP (37.5) } \\
\text { TGB (1)+GBP (18.75) } \\
\text { TGB }(0.75)+\text { GBP }(14.1) \\
\text { TGB }(0.5)+\text { GBP }(9.4)\end{array}$ & $\begin{array}{l}8.8(7.8-9.8) \\
\mid 3.0(\mid 2.2-13.8)^{* * * *} \\
|1| .0(|0.2-| 1.8)^{* * *} \\
10.5(9.5-\mid 1.5)^{*} \\
9.2(8.4-10.2)\end{array}$ \\
\hline $1: 3$ & $\begin{array}{l}\text { Control } \\
\text { TGB (I)+GBP }(56.25) \\
\text { TGB }(0.5)+\text { GBP }(28.1) \\
\text { TGB }(0.25)+\text { GBP }(14.0) \\
\text { TGB }(0.125)+\text { GBP }(7.0)\end{array}$ & $\begin{array}{l}7.9(7.1-8.8) \\
13.4(\mid 2.5-14.4)^{* * * *} \\
10.4(9.5-1 \mid .4)^{* * * * *} \\
9.2(8.4-10.0)^{*} \\
8.3(7.5-9.2)\end{array}$ \\
\hline
\end{tabular}

Results are presented as a current strength (in $\mathrm{mA}$ ) needed to evoke convulsions in $50 \%$ of the animals tested. Statistical analysis of data was performed with a computer program based on log-probit analysis elaborated by Litchfield and Wilcoxon (1949). F-fixed-ratio drug dose combination (eg 1:3 was the drug mixture composed of $25 \%$ of TGB and $75 \%$ of GBP); CS $_{50}$ mix - current strength of respective mixture combinations, obtained directly from the experimental procedure of isobolographic analysis. $* P<0.05$; *** $P<0.0$ I; $* * * * P<0.00$ I vs respective control groups. To construct isoboles and the line of additivity, TGB $(4 \mathrm{mg} / \mathrm{kg})$ and GBP $(75 \mathrm{mg} / \mathrm{kg})$ were used as the reference values. For more detailed information, see Materials and methods.

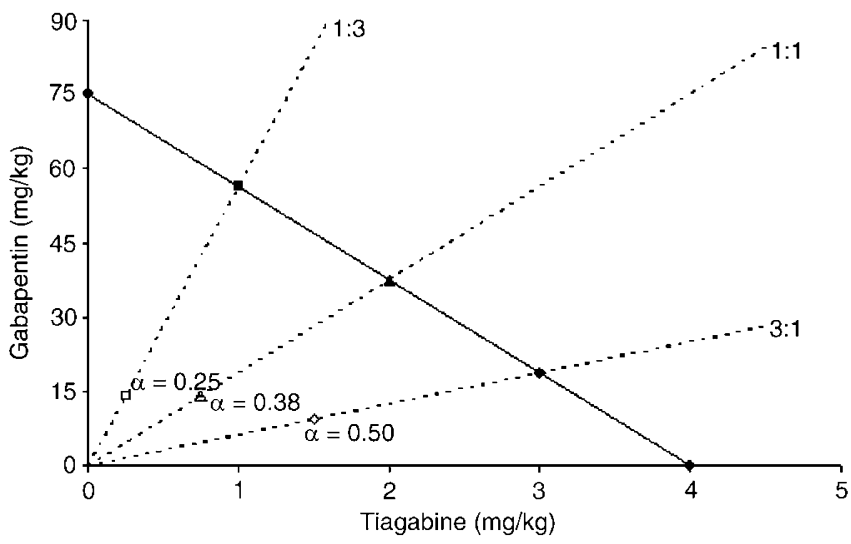

Figure I Isobologram displaying supra-additive (synergistic) interactions between TGB and GBP for three fixed-ratio drug combinations in the electroconvulsive threshold test in mice. The doses of TGB and GBP are plotted on the $X$-and $Y$-axis, respectively. Dotted lines relate to the ratio of drug doses and represent on the graph the $1: 3,1: 1$, and $3: 1$ fixed dose ratio combinations. The solid symbols $(\boldsymbol{\Delta} \boldsymbol{\Delta})$ depict the theoretical additive points for total doses, expressed as the proportion of TGB and GBP that produce an equivalent $50 \%$ effect. The experimental points for TGB + GBP mixture (open symbols: $\square \Delta \diamond$ ) were found to be significantly below the theoretical additive line, indicating the supra-additive (synergistic) interactions. For more details and information, see the section of Materials and methods, and the legend of Table I. $\boldsymbol{\alpha}$-Interaction index describes the magnitude and strength of interaction between the drugs isobolographically tested.

\section{Motor Impairment}

TGB at the dose of $4 \mathrm{mg} / \mathrm{kg}$ and GBP at $75 \mathrm{mg} / \mathrm{kg}$ (applied at doses raising the electroconvulsive threshold) had no 
Table 2 Influence of TGB and GBP in Combinations upon Motor Coordination in the Chimney Test in Mice

\begin{tabular}{lccc}
\hline Treatment (mg/kg) & $\mathbf{F}$ & $\mathbf{N}$ & Mice impaired (\%) \\
\hline Control & & 20 & 0 \\
TGB (4) & & 20 & 10 \\
GBP (75) & 20 & 0 \\
TGB (I)+GBP (56.25) & $1: 3$ & 20 & 5 \\
TGB (2)+GBP (37.5) & $1: 1$ & 20 & $30 *$ \\
TGB (3)+GBP ( I 8.75$)$ & $3: 1$ & 20 & 10 \\
\hline
\end{tabular}

Results are presented as a percentage of animals showing motor deficits in the form of inability to climb backwards up the plastic tube within $60 \mathrm{~s}$ in the chimney test. F-fixed-ratio combination; $N$-number of animals tested.

Statistical analysis was performed using Fischer's exact probability test; $* P<0.05$ vs vehicle-treated animals.

impact on the performance of mice in the chimney test. Coadministration of TGB $(2 \mathrm{mg} / \mathrm{kg})$ with GBP $(37.5 \mathrm{mg} / \mathrm{kg})$ at a fixed-ratio of $1: 1$ caused a significant (at $P<0.05$; Fisher's test) impairment of motor coordination (six out of 20 mice did not climb backwards up the transparent plastic tube within $60 \mathrm{~s}$, and were classified as unable to perform this test). Obviously, all control animals performed the chimney test correctly. On the contrary, both drugs in combinations neither at fixed-ratio of $1: 3$, nor $3: 1$ showed distinct motor deficits in the chimney test (Table 2).

\section{Dark-Avoidance Acquisition and Retention Testing}

The influence of TGB and GBP administered alone or in three fixed-ratio combinations of $1: 3,1: 1$, and $3: 1$, on long-term memory processes (acquisition, consolidation, and retrieval) in mice, was evaluated in three standard variants of the step-through passive avoidance test according to Venault et al (1986). Statistical analysis of data revealed that exclusively all combinations, in variant $\mathrm{A}$ of the passive avoidance test, significantly impaired the longterm memory of the mice, when the drugs were administered before the training session on the first day. TGB at the dose of $1 \mathrm{mg} / \mathrm{kg}$ coadministered with GBP $(56.25 \mathrm{mg} / \mathrm{kg}$ ) (ie at the fixed-ratio of $1: 3$ ) significantly shortened the retention time from 180 to $57.5 \mathrm{~s}$ (at $P<0.001 v s$ control group; $P<0.01$ vs TGB $(1 \mathrm{mg} / \mathrm{kg}) ; \quad P<0.05 \quad v s \quad$ GBP $(56.25 \mathrm{mg} / \mathrm{kg}))$ (Table 3, Figure 2). Similarly, the drugs at the fixed-ratio combination of $1: 1$ (TGB $(2 \mathrm{mg} / \mathrm{kg})+\mathrm{GBP}$ $(37.5 \mathrm{mg} / \mathrm{kg}))$ considerably impaired the long-term memory of the animals tested, reducing the retention time from 180 to $30 \mathrm{~s}$ (at $P<0.001 v s$ control group; $P<0.01 v s$ TGB ( $2 \mathrm{mg} /$ $\mathrm{kg}$ ) or GBP $(37.5 \mathrm{mg} / \mathrm{kg})$ ) (Table 3, Figure 2). Moreover, TGB $(3 \mathrm{mg} / \mathrm{kg})+\mathrm{GBP}(18.75 \mathrm{mg} / \mathrm{kg})$ disturbed the longterm memory, significantly shortening the retention time from 180 to $30 \mathrm{~s}$ (at $P<0.001 v s$ control group; $P<0.001 v s$ GBP $(18.75 \mathrm{mg} / \mathrm{kg}) ; P<0.01$ vs TGB $(3 \mathrm{mg} / \mathrm{kg})$ ) (Table 3 , Figure 2). Furthermore, TGB and GBP - in the same drugdose combinations, did not influence significantly the retention time evaluated in variants $B$ and $C$ of the passive avoidance task (Table 4). After lengthening the exposure time to the current stimulus (from 2 to $6 \mathrm{~s}$ - from the pain threshold test) in variant $A$ of the step-through passive avoidance test, it was evident that the examined combinations of TGB with GBP did not impair the long-term memory in mice (Table 5).
Table 3 Effects of the Combinations of TGB and GBP on LongTerm Memory in Mice - Variant A of the Passive Avoidance Test

\begin{tabular}{|c|c|c|}
\hline $\mathbf{F}$ & Treatment (mg/kg) & Retention (s) \\
\hline $1: 3$ & $\begin{array}{l}\text { Control } \\
\text { TGB (I) } \\
\text { GBP ( } 56.25) \\
\text { TGB (I)+GBP (56.25) }\end{array}$ & $\begin{array}{l}\mid 80(\mid 80-180) \\
\mid 80(\mid 38.75-180) \\
\mid 80(\mid 20-180) \\
57.5(21.25-80)^{a, b, c}\end{array}$ \\
\hline $1: 1$ & $\begin{array}{l}\text { TGB (2) } \\
\text { GBP (37.5) } \\
\text { TGB (2)+GBP (37.5) }\end{array}$ & $\begin{array}{l}180(120-180) \\
180(161.25-180) \\
30.0(25.0-55.0)^{\mathrm{a}, \mathrm{d}}\end{array}$ \\
\hline $3: 1$ & $\begin{array}{l}\text { TGB (3) } \\
\text { GBP (18.75) } \\
\text { TGB (3)+GBP ( } 18.75)\end{array}$ & $\begin{array}{l}180(135-180) \\
180(180-180) \\
30.0(21.25-57.5)^{\mathrm{a}, \mathrm{e}, \mathrm{f}}\end{array}$ \\
\hline
\end{tabular}

Data are expressed as median times (retention in seconds; with 25 and 75 percentiles in parentheses). Retention was measured as a time in which the animal avoids the entrance into the dark box. The drugs were administered (i.p.) before the training session on the first day (at times scheduled from the MESTtest) while the final test reading was performed on the next day ( $24 \mathrm{~h}$ later). Statistical analysis of data was performed with using the Kruskal-Wallis nonparametric ANOVA test followed by pos hoc Dunn's test.

${ }^{a} P<0.00$ I vs control group (vehicle-treated animals)

${ }^{\mathrm{b}} \mathrm{P}<0.0$ I vs TGB $(\mathrm{I} \mathrm{mg} / \mathrm{kg})$

${ }^{c} P<0.05$ vs GBP $(56.25 \mathrm{mg} / \mathrm{kg})$

${ }^{\mathrm{d}} P<0.0$ I vs TGB $(2 \mathrm{mg} / \mathrm{kg})$ and GBP $(37.5 \mathrm{mg} / \mathrm{kg})$.

e $P<0.001$ vs GBP $(18.75 \mathrm{mg} / \mathrm{kg})$.

${ }^{f} P<0.0$ I vs TGB (3 mg/kg). TGB — tiagabine; GBP_-gabapentin.

\section{Pain Threshold Testing}

TGB at $4 \mathrm{mg} / \mathrm{kg}$ significantly lengthened the median latency from 1.5 to $6 \mathrm{~s}(P<0.01)$, while GBP, up to the maximal tested dose of $75 \mathrm{mg} / \mathrm{kg}$, was without any significant effect on this parameter in the pain threshold test in mice (Table 6). Moreover, all combinations of TGB with GBP at fixed-ratios of $1: 3,1: 1$, and $3: 1$, lengthened the median latency from 1.5 to $3.5,3$, and $4 \mathrm{~s}$, respectively (Table 6). The Kruskal-Wallis nonparametric ANOVA test followed by post hoc Dunn's test also revealed a significant increase in median latency for the combination of TGB $(3 \mathrm{mg} / \mathrm{kg})$ with GBP $(18.75 \mathrm{mg} / \mathrm{kg})$, when compared with the control group (vehicle-treated animals) (at $P<0.01)$ (Figure 3).

\section{Influence of TGB on the Plasma and Brain Concentrations of GBP}

$\mathrm{TGB}$, at the doses of 1,2 , and $3 \mathrm{mg} / \mathrm{kg}$ for respective fixedratio combinations, did not affect the plasma level of GBP $(56.25,37.5$, and $18.75 \mathrm{mg} / \mathrm{kg}$, respectively), determined by using the HPLC-technique (Table 7). Moreover, TGB did not affect the free concentration of GBP evaluated in cerebral supernatants for all fixed-ratio $(1: 3,1: 1$ and $3: 1)$ combinations tested (Table 7).

\section{DISCUSSION}

The results obtained in our study clearly demonstrate that interactions between TGB and GBP fulfill the theoretical criterion for advantageous combinations exactly. Both drugs exerted supra-additive (synergistic) interactions as regards their protective activity against electroconvulsions 


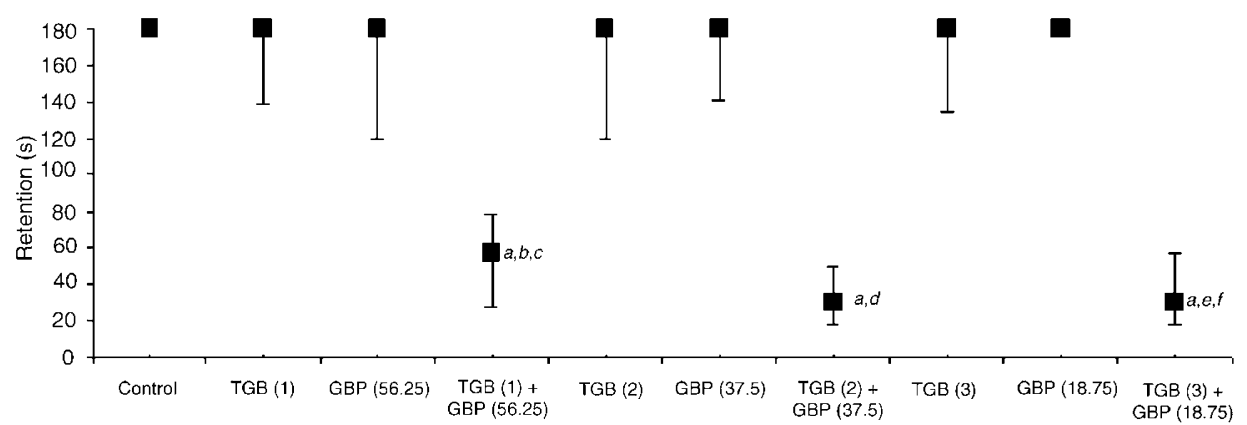

Figure 2 Influence of TGB in combinations with GBP on the long-term memory in the passive avoidance test in mice (variant A). Results are presented as median times (in seconds; with 25 and 75 percentiles as the error bars). Statistical analysis was performed by the Kruskal-Wallis nonparametric ANOVA test followed by post hoc Dunn's test. ${ }^{a} P<0.00$ I vs control group; ${ }^{b} P<0.0$ I vs TGB (I mg/kg); ${ }^{c} P<0.05$ vs GBP $(56.25 \mathrm{mg} / \mathrm{kg}) ;{ }^{\mathrm{d}} P<0.0$ I vs TGB $(2 \mathrm{mg} / \mathrm{kg})$ and $\operatorname{GBP}(37.5 \mathrm{mg} / \mathrm{kg}) ;{ }^{e} P<0.00 \mathrm{I}$ vs GBP $(18.75 \mathrm{mg} / \mathrm{kg}){ }^{\mathrm{f}} P<0.0$ I vs TGB $(3 \mathrm{mg} / \mathrm{kg})$. TGB — tiagabine; GBP_gabapentin.

Table 4 Effects of the Combinations of TGB and GBP on LongTerm Memory in Mice — variants B and C of the Step-Through Passive Avoidance Task

\begin{tabular}{|c|c|c|c|}
\hline \multirow[b]{2}{*}{$\mathbf{F}$} & \multirow[b]{2}{*}{$\begin{array}{c}\text { Treatment (mg/ } \\
\text { kg) }\end{array}$} & \multicolumn{2}{|c|}{ Retention (s) } \\
\hline & & Variant B & Variant C \\
\hline $1: 3$ & $\begin{array}{l}\text { Control } \\
\text { TGB (I) } \\
\text { GBP (56.25) } \\
\text { TGB (I)+GBP (56.25) }\end{array}$ & $\begin{array}{l}180(\mid 80-180) \\
\mid 80(|35-| 80) \\
180(\mid 80-180) \\
\mid 80(98.75-\mid 80)\end{array}$ & $\begin{array}{l}\mid 80(\mid 80-180) \\
\mid 80(\mid 80-180) \\
\mid 80(|80-| 80) \\
\mid 80(|53.75-| 80)\end{array}$ \\
\hline$|:|$ & $\begin{array}{l}\text { TGB (2) } \\
\text { GBP (37.5) } \\
\text { TGB (2)+GBP (37.5) }\end{array}$ & $\begin{array}{l}180(123.75-180) \\
180(180-180) \\
180(\mid 16.25-180)\end{array}$ & $\begin{array}{l}180(180-180) \\
180(180-180) \\
180(165-180)\end{array}$ \\
\hline $3: 1$ & $\begin{array}{l}\text { TGB (3) } \\
\text { GBP (18.75) } \\
\text { TGB (3)+GBP (18.75) }\end{array}$ & $\begin{array}{l}180(161.25-180) \\
180(116.25-180) \\
180(123.75-180)\end{array}$ & $\begin{array}{l}180(146.25-180) \\
180(180-180) \\
\mid 80(108.75-180)\end{array}$ \\
\hline
\end{tabular}

Presented data are medians of the time retention (in seconds; with 25 and 75 percentiles in parentheses). Statistical analysis of data was performed with using the Kruskal-Wallis nonparametric ANOVA test followed by post hoc Dunn's test. In variant $B$ - the drugs were given to animals immediately after the training session on the first day, whereas the final test reading was performed on the next day. In variant $\mathrm{C}$ - the naïve animals were pretrained on the first day, while the drugs were (i.p.) administered $24 \mathrm{~h}$ later, at the times scheduled from the MEST-test. TGB — tiagabine; GBP — gabapentin.

in the MEST-test in mice. TGB and GBP, when combined at subthreshold doses, considerably elevated the electroconvulsive threshold. The strength and magnitude of interaction, expressed in the form of the interaction index for all fixed-ratio combinations, testified a very profitable interaction between TGB and GBP. In our study, the interaction indices ranged between 0.25 and 0.50 , which argues for distinct synergy observed between the drugs. One can suggest that the combination of TGB with GBP at the fixedratio of $1: 3$ exerted a stronger anticonvulsant effect against MEST-test (interaction index was 0.25 ) than the drug mixture in a combination of $3: 1$, in which TGB prevailed (interaction index was 0.50 ).

Considering the doses of TGB and GBP administered separately in the MEST-test, which raised the electroconvulsive threshold in mice, it was intriguing whether both
Table 5 Effects of the Combinations of TGB and GBP on the Long-Term Memory in Mice-Modified Variant A of the Passive Avoidance Task

\begin{tabular}{ll}
\hline Treatment $(\mathbf{m g} / \mathbf{k g})$ & Retention (s) \\
\hline Control & $180(180-180)$ \\
TGB (4) & $110(35-180)$ \\
GBP (75) & $180(105.5-180)$ \\
TGB (I)+GBP (56.25) & $180(180-180)$ \\
TGB (2)+GBP (37.5) & $180(180-180)$ \\
TGB (3)+GBP (18.75) & $180(145.3-180)$ \\
\hline
\end{tabular}

Data are medians of the retention times (in seconds; with 25 and 75 percentiles in parentheses). Results were statistically analyzed with the Kruskal-Wallis nonparametric ANOVA test followed by post hoc Dunn's test. In modified variant $A$ - the exposure time to the 'negative learning stimulus' was prolonged from 2 to $6 \mathrm{~s}$ (from the pain threshold test). TGB - tiagabine;

GBP_-gabapentin

Table 6 Influence of TGB and GBP Administered Singly or in Combinations on the Latency to Pain Reaction in Mice

\begin{tabular}{lccl}
\hline & & \multicolumn{2}{c}{ Latency (s) } \\
\cline { 3 - 4 } Treatment (mg/kg) & F & Median $(\mathbf{2 5 , 7 5}$ percentiles) & Mean/N \\
\hline Control & & $1.5(0.5-1.5)$ & $1.2 / 9$ \\
TGB (I) & $1.5(1.0-2.4)$ & $1.7 / 10$ \\
TGB (2) & $2.5(1.3-5.8)$ & $3.7 / 10$ \\
TGB (3) & $2.0(1.0-8.0)$ & $4.6 / 9$ \\
TGB (4) & $6.0(4.3-10.0) * *$ & $7.1 / 11$ \\
GBP (18.75) & & $2.5(2.0-4.8)$ & $3.1 / 10$ \\
GBP (37.5) & $1.8(1.5-2.4)$ & $2.2 / 10$ \\
GBP (56.25) & & $2.0(2.0-3.8)$ & $2.7 / 10$ \\
GBP (75) & & $2.0(1.5-4.8)$ & $3.4 / 10$ \\
TGB (I)+GBP (56.25) & $1: 3$ & $3.5(2.6-5.0)$ & $4.3 / 9$ \\
TGB (2)+GBP (37.5) & $1: 1$ & $3.0(2.0-5.8)$ & $4.4 / 10$ \\
TGB (3)+GBP (18.75) & $3: 1$ & $4.0(3.0-14.0) * *$ & $7.0 / 9$ \\
\hline
\end{tabular}

Data are presented as the median latency (in seconds; with 25 and 75 percentiles in parentheses). Statistical analysis was performed by the use of Kruskal-Wallis nonparametric ANOVA test followed by post hoc Dunn's test. $\mathrm{F}$-fixed-ratio combinations. $* * * 0.0$ I vs the control group (vehicle-treated animals).

Alternatively, data are presented as mean latency (in seconds); N-number of animals tested.

drugs combined at various fixed-ratio combinations would interact together, potentiating their anticonvulsant activity. To perform this study and determine the exact types of 


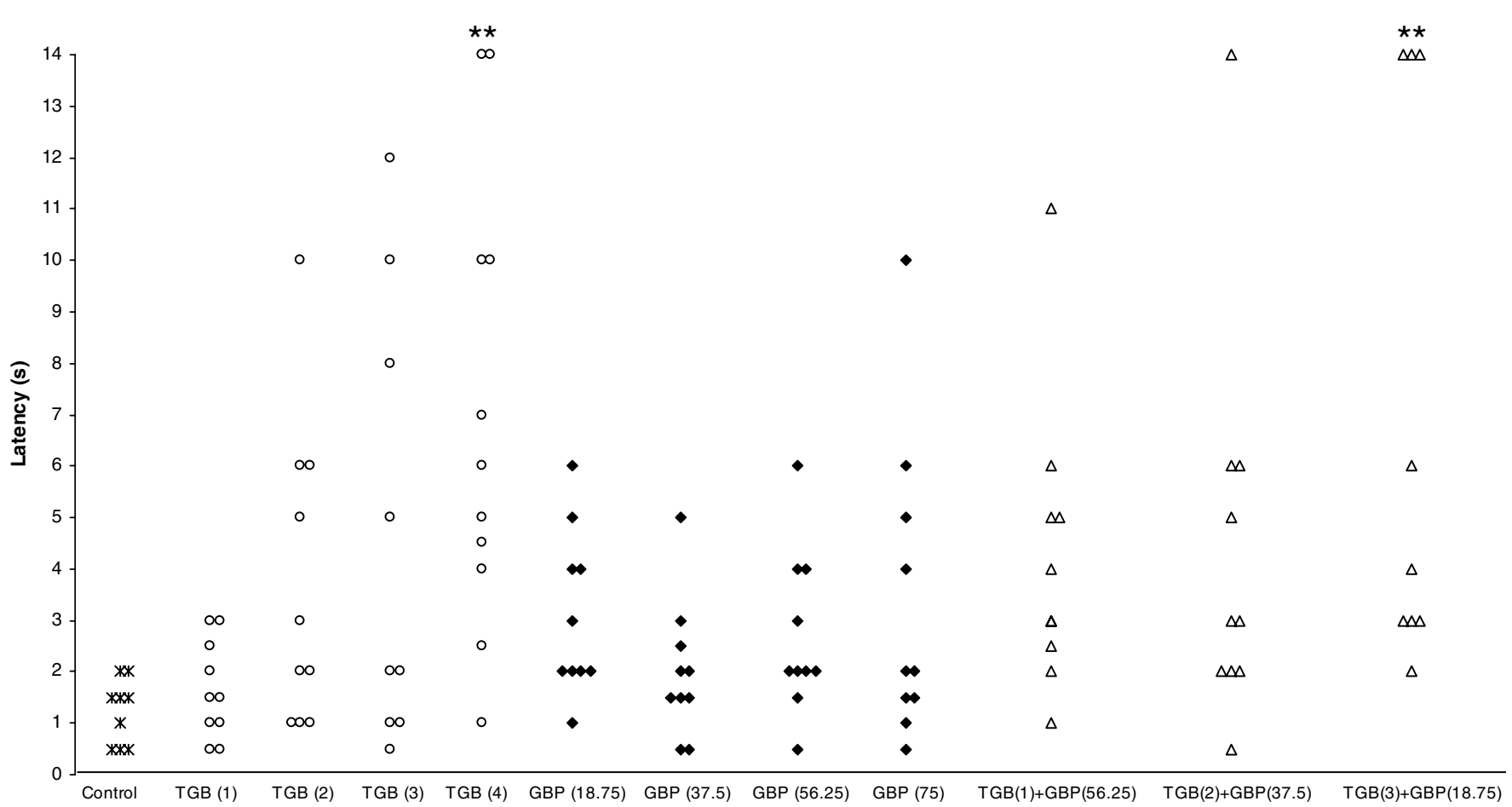

Figure 3 Effects of TGB and GBP alone or in combinations on the latency to first pain reaction in mice. Results are presented as the latency (in seconds) to the first pain reaction in animals. Statistical analysis was performed by the use of the Kruskal-Wallis nonparametric ANOVA test followed by post hoc Dunn's test. $* * * 0.0$ I vs the control group (vehicle-treated animals).

Table 7 Influence of TGB on the Plasma and Brain Concentrations of GBP

\begin{tabular}{lccc}
\hline Treatment $(\mathbf{m g} / \mathbf{k g})$ & $\mathbf{F}$ & Plasma level $(\boldsymbol{\mu g} / \mathbf{m l})$ & Brain concentration $(\boldsymbol{\mu g} / \mathbf{g})$ \\
\hline GBP $(56.25)$ & & $21.82 \pm 5.50$ & $10.52 \pm 2.03$ \\
GBP (56.25)+TGB (I) & $1: 3$ & $22.73 \pm 3.72$ & $11.88 \pm 1.69$ \\
GBP (37.5) & & $9.34 \pm 3.66$ & $6.66 \pm 1.87$ \\
GBP (37.5)+TGB (2) & $1: 1$ & $11.42 \pm 3.65$ & $6.12 \pm 1.36$ \\
GBP (18.75) & & $8.31 \pm 1.08$ & $4.04 \pm 1.03$ \\
GBP (18.75)+TGB (3) & $3: 1$ & $7.30 \pm 1.01$ & $4.05 \pm 1.05$ \\
\hline
\end{tabular}

Presented values are means in $\mu \mathrm{g} / \mathrm{ml}$ of plasma $\pm \mathrm{SD}$, or in $\mu \mathrm{g} / \mathrm{g}$ of wet brain tissue \pm SD of at least eight determinations. F-fixed-ratio combination. Blood samples and brain homogenates were taken at times scheduled for the electroconvulsive threshold test. Unpaired Student's t-test was used for the statistical evaluation of the data.

interactions between TGB and GBP, a method of calculation of additive drug-dose mixtures exclusively was based upon the isobolographic analysis. With 'isobolographic-like analysis', it was observed that the drug-dose mixture, theoretically determined to be additive (from the line of additivity), raised the $\mathrm{CS}_{50}$ values much more significantly than it was primarily expected from additivity, proving the existence of synergy between drugs. In such cases, a higher current strength was required to induce a $50 \%$ hindlimb extension in mice. After receiving the theoretical additive doses of AEDs in animals, the current strength values were statistically analyzed as quantal data, but not the drug doses, as it has been widely accepted with isobolography. Nevertheless, the applied isobolographiclike method allowed the proper assessment of synergistic interactions between TGB and GBP in the MEST-test in mice.
The experimental and clinical evidence indicate that GBP and TGB act through different mechanisms of action related with GABA-ergic neurotransmitter system (see Introduction). Therefore, it is conceivable that diverse mechanisms of action of both drugs complete each other, potentiating their anticonvulsant effect against electroconvulsions. It is widely accepted that TGB and GBP are virtually ineffective in the MES-test in mice (at therapeutically relevant concentrations); however, both drugs significantly raise the threshold for electroconvulsions (Rogawski and Porter, 1990). Nevertheless, it has been shown that TGB is active in MES-test only at doses two- to three-fold higher than those producing motor impairment (more than $40 \mathrm{mg} / \mathrm{kg}$; i.p.) (White, 1997). GBP at the dose of approximately $10 \mathrm{mg} / \mathrm{kg}$; i.p., reduces MES-induced convulsions in rats, although the drug was reported to be completely inactive in mice (for a review, see Rogawski and Porter, 1990). 
The MES-test is considered as an animal model of generalized tonic-clonic seizures and, to a certain extent, of partial, secondarily generalized convulsions in humans (Fisher, 1989; Löscher and Schmidt, 1988; Löscher et al, 1991). Furthermore, there exists a suggestion that MESTtest often predicts drugs effective in partial secondarily generalized tonic-clonic seizures in humans, being much more sensitive than traditional MES-test (Löscher et al, 1991). This observation has important implications pertinent to the further use of TGB and GBP in clinical practice. In our study, it was found that combinations of TGB with GBP protect animals against maximal (tonic) hindlimb extension in the MEST-test. Moreover, some clinical trials have revealed that TGB and GBP administered alone protect patients with refractory partial and secondarily generalized tonic-clonic seizures, as well as, both drugs separately have shown promising effects against focal, secondarily generalized seizures in humans (Chadwick et al, 1996, 1998; Kalviainen et al, 1998; Uthman et al, 1998).

As yet, for rational polytherapy, there is no consensus on whether to combine the AEDs affecting the same neurotransmitter system and reach a stronger therapeutic effect or choose the AEDs influencing diverse neurotransmitter systems. Theoretical considerations concerning the most efficacious combinations of AEDs, based on different mechanisms of action of component drugs, were partially confirmed in some experimental studies. In DBA $/ 2$ mice, it was observed that coadministration of two agents influencing the inhibitory GABA-ergic or excitatory amino acid (EAA) neurotransmitter systems were effective in terms of the reduction of seizures (Klitgaard et al, 1993). When combining diazepam $\left(\mathrm{GABA}_{\mathrm{A}}\right.$ receptor agonist) with $\mathrm{NNC}$ 05-0711 (GABA uptake inhibitor into neurons and glia) - $\ominus$ both substances activating the GABA inhibitory neurotransmitter system; or NBQX (a competitive AMPA/kainate receptor antagonist) with CGP 39551 (a competitive ionotropic NMDA receptor antagonist)-both agents inhibiting the EAA neurotransmitter system - the combinations had a synergistic character of interactions. In contrast, when combining diazepam with CGP 39551; diazepam with NBQX; NNC 05-0711 with CGP 39551, or NNC 05-0711 with NBQX - the interactions were merely additive (Klitgaard et al, 1993). Reflecting the fact that the activation of the same (GABA-ergic) neurotransmitter system exerts synergy in seizure control in experimental model of epilepsy, it seems possible that the combinations of TGB with GBP may also be efficacious in patients with drug-resistant epilepsy, providing the most effective treatment regimen. Some existing clinical data indicate that coadministration of TGB with vigabatrin (VGB), two drugs exclusively influencing the GABA-ergic system, may considerably improve the control of seizure attacks (Leach and Brodie, 1994). The synergistic interaction observed between these AEDs was not casual because it was experimentally confirmed that lower doses of VGB coadministered with TGB significantly reduced GABA uptake from synaptic clefts (Leach et al, 1996), resulting in the increase of GABA in the whole mouse neocortex (Leach et al, 1997). Moreover, the drugs applied together, transiently reduced experimentally induced epileptic discharges from the hippocampus, while the previous incubation with VGB, followed by addition of TGB (after $2 \mathrm{~h}$ of incubation with VGB), drastically and firmly inhibited the epileptic potentials from hippocampal slices of guineapigs (Kohling et al, 2002). Similarly, in an in vitro study, conducted also on hippocampal slices of guinea-pigs, it was observed that the administration of GBP alone, had no impact on GABA release, however, some important changes in GABA release were observed after the pretreatment with VGB (Lucke et al, 1998). The AEDs' cooperation within the same neurotransmitter system (GABA-ergic) is very intriguing from either experimental or clinical points of view. Available data (evaluated isobolographically in the electroconvulsive tests in mice) have shown that TGB in combination with other AEDs, possessing the GABA-ergic component, exerted: (1) synergy, when combined with VPA - this interaction had a rather pharmacokinetic character related with the elevation of VPA-concentration within the brain tissue of the animals; or (2) additivity, for the combinations of TGB with PB or TPM (Luszczki et al, $2003 \mathrm{~b})$. On the other hand, interactions of GBP with other GABA enhancers revealed that GBP in combination with VPA or PB exerted synergy (Borowicz et al, 2002). Interactions of TGB with other GABA enhancers, such as benzodiazepines and VGB or GBP with VGB, TPM, and benzodiazepines were not yet isobolographically investigated. Nevertheless, the synergic type of interactions between TGB and GBP; TGB and VPA; GBP and VPA, or GBP and $\mathrm{PB}$ - that corroborated experimentally in mice with isobolography, may suggest that activation of various mechanisms within the same neurotransmitter system may exert advantageous effects, offering the patients a significant reduction in seizure frequency; however, it should be clinically confirmed. From a theoretical point of view, it seems likely that the restoration of equilibrium in the epileptogenic focus in the brain through the moderate activation of GABA system may be clinically useful during the combined therapy. As yet, in medical literature, there is no clinical report presenting the efficacious combined treatment with GBP and TGB.

It should be emphasized that either TGB or GBP have lately been introduced into clinical practice. The fundamental rule during combined treatment with AEDs in patients with drug-resistant epilepsy is that an adjuvant drug (usually a novel one) is coadministered with conventional AEDs (carbamazepine, phenytoin, phenobarbital, or valproate). This scheme of add-on therapy eliminates and drastically reduces the possibility of application of two novel AEDs in combination. One can ascertain that combinations based exclusively on novel AEDs are scarce in clinical practice, depending exclusively on neurologists' knowledge of theoretical AED mechanisms of action. On the other hand, there is a trend towards the previous examination of all theoretically advantageous AED-combinations in animal models of epilepsy, and subsequently only these, which show synergy, should be 'empirically tested' in clinical practice. So far, the combination investigated in the present study between TGB and GBP should be verified in further clinical practice, giving precise indications on extrapolation of such an experimental study to clinical conditions, which might contribute to the finding of the most efficacious mode of treatment the patients with intractable seizures.

Drugs applied in combinations during polytherapy sometimes exert a very profitable anticonvulsant effect 
resulting from synergistic interactions. Some authors often ascribe this effect to a novel or conventional AED added to previously established monotherapy. Such suggestions are frequently erroneous because the observed antiseizure effect generally depends on both drugs applied in combination, but not solely on an added drug. There is no doubt that drugs, in vivo, cooperate together and the final result (anticonvulsant effect) is always related to pharmacokinetic and/or pharmacodynamic interactions involved in seizure control during the combined therapy.

The problem of safety, efficacy, and tolerability of the applied bitherapy has to be kept in mind when considering the overall biological and adverse effects of these AEDs. The possibility of some pharmacokinetic interactions should always be considered during the polytherapy of refractory seizures. From a pharmacokinetic point of view, it is important to note that GBP does not undergo a biotransformation and is entirely eliminated, without being metabolized, in urine. In contrast, TGB is extensively metabolized in the liver and only a small portion (less than $1 \%$ ) of the dose is excreted unchanged in urine (Bourgeois, 1995). Another interesting property of GBP is a total lack of plasma protein binding, in contrast to TGB, which is highly bound to plasma proteins (96\%) (Rambeck et al, 1996). In light of these facts, theoretically, the combinations of TGB with GBP should exert no pharmacokinetic interaction in clinical conditions.

A growing body of evidence suggests that the proper classification of pharmacologic interactions among AEDs should be followed by evaluation of pharmacokinetic events, which may sometimes influence the final effect of the observed interactions. There is no doubt that by ignoring the pharmacokinetic character of interactions among AEDs, one can misinterpret the isobolographic types of interactions evaluated in preclinical studies (Cadart et al, 2002). Therefore, it seems clear that the concomitant determination of anticonvulsant efficacy of the two-drug mixture with AED-concentrations in the biophase, may give much more insight into the exact character of interactions among AEDs. This suggestion is generally consistent with our earlier study (Luszczki et al, 2003b) and the studies of Cadart et al (2002), Bourgeois (1986, 1988) and Bourgeois and Wad (1984, 1988), who had additionally evaluated a pharmacokinetic character of interactions among AEDs in the cerebrospinal fluids or brains of animals tested. In our opinion, the determination of AED-concentrations in the homogenates of animal brain tissue seems the most optimal resolution for the exact determination and classification of two-drug interactions. It is worth mentioning that, in our study, TGB affected neither the free plasma levels nor brain concentrations of GBP, determined by the use of the HPLCtechnique, for all fixed-ratio combinations.

The step-through passive avoidance task allowed the determination of influence of AEDs upon the long-term memory of animals, in three variants of this test. It is widely accepted that variant $\mathrm{A}$ of the passive avoidance task determines effects of the drugs on learning and memorizing processes in animals (acquisition); variant B allows testing the drugs' influence on consolidation of previously remembered factors and learning stimuli in animals, and variant $\mathrm{C}$, determines the effects of the drugs on retrieval and remembering the inducing events (Venault et al, 1986;
Parada-Turska and Turski, 1990). Testing the influence of TGB and GBP in combinations, it seemed clear that only combinations of TGB with GBP in variant A impaired the long-term memory in animals. All remaining combinations tested in variants $\mathrm{B}$ and $\mathrm{C}$ were without any significance on long-term memory in mice. There are some opposing literature data concerning the impairment of the long-term memory in animals after administration of TGB and/or GBP, therefore, it became important to thoroughly examine the selective impairment of cognitive functions in animals.

In the passive avoidance test, it has been observed that the mice, after administration of competitive and/or noncompetitive NMDA antagonists before the training session (variant A), have shown significant impairment of acquisition of the task (Parada-Turska and Turski, 1990). The administration of the same drugs (at the same conditions), however, directly after the training session (variant B), or $24 \mathrm{~h}$ later (variant $\mathrm{C}$ ) did not impair the longterm memory in mice. In contrast, the application of NMDA allowed the animals to recall and avoid the entrance into the dark box. The authors have suggested that either NMDA or enhancement of the EAA neurotransmission may ameliorate the learning processes in the animals tested (ParadaTurska and Turski, 1990). One can suggest that activation of GABA-ergic inhibitory neurotransmitter system should impair the learning processes in animals, analogously as it has been shown in the case of NMDA antagonists.

Nevertheless, it has to be mentioned that TGB (at the dose of $20 \mathrm{mg} / \mathrm{kg}$ ) exerted the impairment of spatial learning in the Morris water-maze test in rats (Schmitt and Hiemke, 2002). The authors corroborated that the administration of TGB had detrimental effects either on acquisition or retrieval of the task. In contrast, Halonen et al (1996) have shown improved performance of rats in the Morris watermaze test under the treatment with TGB at a dose of $50 \mathrm{mg} /$ $\mathrm{kg}$. One can speculate about the possible TGB's mechanisms responsible for the impairment of acquisition and retrieval in the spatial learning task. Reviewing the literature, it seems that $\mathrm{TGB}$, similar to $\mathrm{GABA}_{\mathrm{A}^{-}}$or benzodiazepinereceptor agonists, evokes the impairment of acquisition and, additionally - in contrast to these agonists, impairs the retrieval of the task. On the other hand, in patients with epilepsy, TGB and other GABA enhancers, such as GBP or VGB improved memory and cognitive functions (Kalviainen, 1998; Kalviainen et al, 1995; Mortimore et al, 1998; Meador et al, 1999). So far, considering the results of our study, as well as available evidence, it is difficult, at present, to unequivocally ascertain whether or not TGB disturbs the memory in animals.

Moreover, examining the propensity of TGB and GBP to induce memory impairment in mice, another problem should be considered. After reviewing medical literature, it became evident that GBP and TGB are the efficacious drugs in reducing acute and chronic pain in the experimental models of nociception (Shimoyama et al, 1997; Hunter et al, 1997; Ipponi et al, 1999; Lu and Westlund, 1999; Laughlin et al, 2002). Moreover, some authors indicated the clinical efficacy of GBP in the treatment of pain neuropathy after herpes zoster (Rowbotham et al, 1998; Rice and Maton, 2001; Serpell et al, 2002), trigeminal neuralgia (Carrazana and Schachter, 1998), peripheral neuropathy in patients with diabetes (Backonja et al, 1998, Backonja, 1999), or 
phantom limb pain (Rusy et al, 2001). With respect to TGB, it has significantly reduced sensitive neuropathy in patients resistant to the standard antinociceptive therapy (Novak et al, 2001).

It should be highlighted that the passive avoidance task in rodents is based on a 'negative learning factor' as a stimulus of direct current $(0.6 \mathrm{~mA}, 2 \mathrm{~s})$ is delivered after the entrance of animals into the dark box of the testing apparatus. Current impulse, through the grid floor of the apparatus, induces pain in the paws of the animals tested. Obviously, each animal quickly recalls this negative learning factor and associates the pain with the entrance into the dark box. The next time ( $24 \mathrm{~h}$ later) the animal, after being put again into the light box, avoids the dark one up to $180 \mathrm{~s}$, recalling the unpleasant experience from the preceding day. This is the fundamental condition for examining the learning processes in animals. Therefore, it is not surprising that the drugs reducing the pain sensitivity to the negative learning factors impair the long-term memory. The anecdotal statement that a pharmacological inhibition of the pain sensitivity can significantly impair the long-term memory in animals is true, because the animals did not remember or recall the factor, which was not experienced. Based upon the observation from the present study, it seemed important to determine the pain threshold for TGB and GBP alone or in combinations. Unexpectedly, TGB elevated the pain threshold in a dose-dependent manner, lengthening the latency time to the first pain reaction. Therefore, after testing the long-term memory in animals in the modified variant $\mathrm{A}$ of the passive avoidance task, it was corroborated that combinations of TGB with GBP did not impair longterm memory in the animals. Thus, it seems evident that the proper assessment of the influence of novel AEDs on the long-term memory in animals should be followed by previous determination of the pain threshold. Obviously, additional (antinociceptive) properties of TGB and GBP, administered in combinations, could ameliorate the patients' quality of living, especially those, who similar to healthy people, suffer from various pain disorders that are or not related with epilepsy, for instance: headaches, algomenorrhoea, etc. (Savoldi et al, 1984; Leniger et al, 2001; Nair et al, 2001). Due to this additional antinociceptive component, combinations of TGB with GBP might become much more efficacious from a clinical point of view.

The pain threshold test confirmed our presumptions that TGB, producing antinociception, may yield false results and negatively influence the long-term memory tested under standard conditions. In our study, the first time we applied the pain threshold testing procedure in order to detect the effects of the novel AEDs-TGB and GBP on the pain reaction. In order to eliminate the analgesic properties of AEDs, which could impair and disturb the processes of long-term memory in animals, the exposure time to stimulus was lengthened from 2 to $6 \mathrm{~s}$ in the step-through passive avoidance task. We consciously changed the time of stimulation, but not the current parameters because it is believed that current with changed intensity or voltage may cause damage of peripheral nerves. So far, the stimulus duration of $6 \mathrm{~s}$ was assigned as a standard and pattern value in the present study.

Another problem, concerning the antiseizure medication with GABA enhancers, should be highlighted here. The existing data indicate that a moderate stimulation of GABAergic neurotransmitter system is responsible for a substantial reduction of seizure attacks. On the other hand, the excessive stimulation may lead to aggravation or enhancement of epileptic convulsions in patients. This clinical worsening, after administration of some AEDs influencing the GABA-ergic system, seems to depend on specific interactions of these AEDs with neuronal circuits in the brain. It is possible that AEDs inhibit some neuronal populations, while the others are overstimulated, finally resulting in pro- or anticonvulsant action of these AEDs (Deckers et al, 2003). The experimental data and clinical reports indicate that overstimulation of GABA-ergic neurotransmission potentiates the epileptic attacks (by increasing their frequency) or induces their new forms (especially, the absence attacks) (Murphy and Delanty, 2000). A growing body of evidence has suggested that clinical use of conventional and novel AEDs may sometimes contribute to the aggravation of seizures (Perucca et al, 1998; Murphy and Delanty, 2000). Among the AEDs, possessing a high propensity for inducing the seizures, there are: VGB, TGB, or GBP - which selectively affect the GABA-ergic system (Loiseau, 1998). Also, it was observed that patients on addon therapy, taking VGB or GBP, two to four times frequently experienced convulsions than patients medicated only with CBZ or VPA (Elger et al, 1998). Existing clinical report shows that GBP worsened myoclonic or absence seizures or activated myoclonic convulsions in partial seizures (Wong et al, 1999). Myoclonic convulsions were also seen after the addition of moderate doses of TGB to the existing monotherapy, whereas after the overtreatment with TGB, a nonconvulsive status epilepticus was observed (Schapel and Chadwick, 1996; Shinnar et al, 2001). Reviewing literature, Perucca et al (1998) have focused attention on two independent, central mechanisms generating the epileptic convulsions in patients treated with AEDs. The first one-nonspecific, dose-dependent, and the second one (pharmacodynamic) - closely related with antiseizure mechanisms of action of AEDs. The proconvulsive mechanism of action of TGB, probably depends on the increase of GABA concentration within the synaptic clefts at the level of the thalamus, with subsequent potentialization of $\mathrm{GABA}_{\mathrm{B}}$-mediated slow hyperpolarization of neurons, which finally leads to amplification of the thalamocortical rhythms necessary to support the spike-wave discharges (White, 1999). Experimental activation of $\mathrm{GABA}_{\mathrm{B}}$ receptors (with baclofen-a $G_{A B A}$ receptor agonist) increases the frequency of absence seizures in pharmacological and genetic models of seizures in animals (Hosford et al, 1992; Snead, 1992).

The results of the present study indicate that, due to the cooperation of TGB with GBP in combinations, it is possible to reduce the drug loads significantly without losing their antiseizure properties. Additionally, the optimal drug-dose application may eliminate and limit to minimum the potentially possible overstimulation of the GABA-ergic system, which might evoke paradoxical seizures. There are some suggestions with respect to the fact that overtreatment in epilepsy is the main cause of paradoxically induced seizures in patients (Bourgeois, 2002; Deckers, 2002; Holmes, 2002; Perucca, 2002; Schmidt, 2002; Schmidt et al, 2002). In such cases, the introduction of another AED 
(third, fourth, fifth) in order to subdue the seizures may develop iatrogenic drug-resistant seizures (vicious circle). Therefore, rational polytherapy should consider the simultaneous reduction of drug doses in order to avoid the druginduced seizures in patients. Moreover, it is conceivable that with reduction of the drug loads, one can diminish the adverse effects of combined AEDs (Czuczwar and Borowicz, 2002).

Summing up, it seems possible that the synergistic cooperation of TGB with GBP (in terms of their protective effects) and subsequent reduction of the drug loads for avoiding some deleterious side effects or paradoxically induced seizures might provide patients with adequate seizure control. In the adjunctive therapy, the coadministration of TGB with GBP might be profitable and worth recommendations in clinical practice. Moreover, combinations of TGB with GBP, owing to their analgesic effects, may yield the appropriate result in the seizure control and be better tolerated than the other AEDs, contributing to the improvement of patients' quality of life and their social functioning. So far, these 'additional properties' of novel AEDs should also be considered by clinicians.

\section{ACKNOWLEDGEMENTS}

This study was supported by Grant No. 6P05D09821 from the State Committee for Scientific Research, Warsaw, Poland. The authors thank Mr Zgrajka (Institute of Agricultural Medicine, Lublin, Poland) for the skillful determination of the plasma and brain concentrations of GBP.

\section{REFERENCES}

Appleton R, Fichtner K, LaMoreaux L, Alexander J, Halsall G, the Gabapentin Pediatric Study Group et al (1999). Gabapentin as add-on therapy in children with refractory partial seizures: a 12week, multicenter, double-blind, placebo-controlled study. Epilepsia 40: 1147-1154.

Backonja MM (1999). Gabapentin monotherapy for the symptomatic treatment of painful neuropathy: a multicenter, doubleblind, placebo-controlled trial in patients with diabetes mellitus. Epilepsia 40(Suppl 6): S57-S59; discussion S73-S74.

Backonja M, Beydoun A, Edwards KR, Schwartz SL, Fonseca V, Hes $M$ et al (1998). Gabapentin for the symptomatic treatment of painful neuropathy in patients with diabetes mellitus: a randomized controlled trial. JAMA 280: 1831-1836.

Ben-Menachem E (1995). International experience with tiagabine add-on therapy. Epilepsia 36(Suppl 6): S14-S21.

Biraben A, Beaussart M, Josien E, Pestre M, Savet JF, Schaff JL et al (2001). Comparison of twice- and three times daily tiagabine for the adjunctive treatment of partial seizures in refractory patients with epilepsy: an open label, randomised, parallel-group study. Epileptic Disord 3: 91-100.

Boissier JR, Tardy J, Diverres JC (1960). Une nouvelle methode simple pour explorer l'action 'tranquilisante': le test de la cheminee. Med Exp (Basel) 3: 81-84.

Borowicz KK, Swiader M, Luszczki J, Czuczwar SJ (2002). Effect of gabapentin on the anticonvulsant activity of antiepileptic drugs against electroconvulsions in mice - an isobolographic analysis. Epilepsia 43: 956-963.

Bourgeois BFD (1986). Antiepileptic drug combinations and experimental background: the case of phenobarbital and phenytoin. Naunyn Schmieldeberg's Arch Pharmacol 333: 406-411.
Bourgeois BFD (1988). Combination of valproate and ethosuximide: antiepileptic and neurotoxic interaction. J Pharmacol Exp Ther 247: 1128-1132.

Bourgeois BFD (1995). Important pharmacokinetic properties of antiepileptic drugs. Epilepsia 36(Suppl 5): S1-S7.

Bourgeois BFD (2002). Reducing overtreatment. Epilepsy Res 52: 53-60.

Bourgeois BFD, Wad N (1984). Individual and combined antiepileptic and neurotoxic activity of carbamazepine and carbamazepine-10,11-epoxide in mice. J Pharmacol Exp Ther 231: 411-415.

Bourgeois BFD, Wad N (1988). Combined administration of carbamazepine and phenobarbital: effect on anticonvulsant activity and neurotoxicity. Epilepsia 29: 482-487.

Brodie MJ (2001). Do we need any more new antiepileptic drugs? Epilepsy Res 45: 3-6.

Cadart M, Marchand S, Pariat C, Bouquet S, Couet W (2002). Ignoring pharmacokinetics may lead to isoboles misinterpretation: illustration with the norfloxacin-theophylline convulsant interaction in rats. Pharmacol Res 19: 209-214.

Carrazana EJ, Schachter SC (1998). Alternative use of lamotrigine and gabapentin in the treatment of trigeminal neuralgia. Neurology 50: 1192.

Chadwick DW, Anhut H, Greiner MJ, Alexander J, Murray GH, the International Gabapentin Monotherapy study Group 945-77 et al (1998). A double-blind trial of gabapentin monotherapy for newly diagnosed partial seizures. Neurology 51: 1282-1288.

Chadwick DW, Leidermann DB, Sauermann W, Alexander J, Garofalo E (1996). Gabapentin in generalized seizures. Epilepsy Res 25: 191-197.

Czuczwar SJ (1998). Experimental basis for rational polytherapy. Epileptologia 6: 231-247.

Czuczwar SJ, Borowicz KK (2002). Polytherapy in epilepsy: the experimental evidence. Epilepsy Res 52: 15-23.

Czuczwar SJ, Patsalos NP (2001). The new generation of GABA enhancers. Potential in the treatment of epilepsy. CNS Drugs 15: 339-350.

Deckers CLP (2002). Overtreatment in adults with epilepsy. Epilepsy Res 52: 43-52.

Deckers CLP, Czuczwar SJ, Hekster YA, Keyser A, Kubova H, Meinardi $\mathrm{H}$ et al (2000). Selection of antiepileptic drug polytherapy based on mechanism of action: the evidence reviewed. Epilepsia 41: 1364-1374.

Deckers CLP, Genton P, Sills GJ, Schmidt D (2003). Current limitations of antiepileptic drug therapy: a conference review. Epilepsy Res 53: 1-17.

Elger CE, Bauer J, Scherrmann J, Widman G (1998). Aggravation of focal epileptic seizures by antiepileptic drugs. Epilepsia 39(Suppl 3): S15-S18.

Fisher RS (1989). Animal models of the epilepsies. Brain Res Rev 14: $245-278$.

Fisher RS, Sachdeo RC, Pellock J, Penovich PE, Magnus L, Bernstein P (2001). Rapid initiation of gabapentin. A randomized, controlled trial. Neurology 56: 743-748.

Gee NS, Brown JP, Dissanayake VUK, Offord J, Thurlow R, Woodruff GN (1996). The novel anticonvulsant drug, gabapentin (neurontin), binds to the $\alpha_{2} \delta$ subunit of calcium channel. J Biol Chem 271: 5768-5776.

Genton P, Roger J (1997). Antiepileptic drug monotherapy versus polytherapy: a historical perspective. Epilepsia 38(Suppl 5): S2-S5.

Goldlust A, Su TZ, Welty DF, Taylor CP, Oxender DL (1995). Effects of anticonvulsant drug gabapentin on the enzymes in metabolic pathways of glutamate and GABA. Epilepsy Res 22: $1-11$.

Halonen T, Nissinen J, Jansen JA, Pitkanen A (1996). Tiagabine prevents seizures, neuronal damage and memory impairment in experimental status epilepticus. Eur J Pharmacol 299: 69-81. 
Holmes GL (2002). Overtreatment in children with epilepsy. Epilepsy Res 52: 35-42.

Hosford DA, Clark S, Cao Z, Wilson WA, Lin FH, Morrisett RA et al (1992). The role of GABAB receptor activation in absence seizures of lethargic (lh/lh) mice. Science 257: 398-401.

Hunter JC, Gogas KR, Hedley LR, Jacobson LO, Kassotakis L, Thompson J et al (1997). The effect of novel anti-epileptic drugs in rat experimental models of acute and chronic pain. Eur $J$ Pharmacol 324: 153-160.

Ipponi A, Lamberti C, Medica A, Bartolini A, Malmberg-Aiello P (1999). Tiagabine antinociception in rodents depends on GABA(B) receptor activation: parallel antinociception testing and medial thalamus GABA microdialysis. Eur J Pharmacol 368: 205-211.

Kalviainen R (1998). Tiagabine: a new therapeutic option for people with intellectual disability and partial epilepsy. J Intellect Disabil Res 42(Suppl 1): 63-67.

Kalviainen R, Aikia M, Saukkonen AM, Mervaala E, Riekkinen Sr PJ (1995). Vigabatrin $v s$ carbamazepine monotherapy in patients with newly diagnosed epilepsy. A randomized, controlled study. Arch Neurol 52: 989-996.

Kalviainen R, Brodie MJ, Duncan J, Chadwick D, Edwards D, Lyby K (1998). A double-blind, placebo-controlled trial of tiagabine given three-times daily as add-on therapy for refractory partial seizures. Northern European Tiagabine Study Group. Epilepsy Res 30: 31-40.

Kerry DW, Hamilton-Miller JMT, Brumfitt W (1975). Trimethoprim and rifampicin: in vitro activities separately and in combination. J Antimicrob Chemother 1: 417-427.

Klitgaard H, Knudsen ML, Jackson HC (1993). Synergism between drugs with different mechanisms of action against audiogenic seizures in DBA/2 mice. Epilepsia 34(Suppl 6): 93-94.

Kohling R, Konig K, Lucke A, Mayer T, Wolf P, Speckmann EJ (2002). Pre- rather than co-application of vigabatrin increases the efficacy of tiagabine in hippocampal slices. Epilepsia 43: $1455-1461$.

Krämer G (1997). The limitations of antiepileptic drug monotherapy. Epilepsia 38(Suppl 5): S9-S13.

Laughlin TM, Tram KV, Wilcox GL, Birnbaum AK (2002). Comparison of antiepileptic drugs tiagabine, lamotrigine, and gabapentin in mouse models of acute, prolonged, and chronic nociception. J Pharmacol Exp Ther 302: 1168-1175.

Leach JP, Brodie MJ (1994). Synergism with GABAergic drugs in refractory epilepsy. Lancet 343: 1650.

Leach JP, Sills GJ, Butler E, Forrest G, Thompson GG, Brodie MJ (1997). Neurochemical actions of gabapentin in mouse brain. Epilepsy Res 27: 175-180.

Leach JP, Sills GJ, Majid A, Butler E, Carswell A, Thompson GG et al (1996). Effects of tiagabine and vigabatrin on GABA uptake into primary cultures of rat cortical astrocytes. Seizure 5: 229-234.

Leniger T, Isbruch K, von den Driesch S, Diener HC, Hufnagel A (2001). Seizure-associated headache in epilepsy. Epilepsia 42: $1176-1179$.

Litchfield JT, Wilcoxon F (1949). A simplified method of evaluating dose-effect experiments. J Pharmacol Exp Ther 96: 99-113.

Loiseau P (1998). Do antiepileptic drugs exacerbate seizures? Epilepsia 39: 2-4.

Löscher W, Fassbender CP, Nolting B (1991). The role of technical, biological and pharmacological factors in the laboratory evaluation of anticonvulsant drugs. II. Maximal electroshock seizure models. Epilepsy Res 8: 79-94.

Löscher W, Schmidt D (1988). Which animal models should be used in the search for new antiepileptic drugs? A proposal based on experimental and clinical considerations. Epilepsy Res 2: 145-181.

$\mathrm{Lu} \mathrm{Y,} \mathrm{Westlund} \mathrm{KN} \mathrm{(1999).} \mathrm{Gabapentin} \mathrm{attenuates} \mathrm{nociceptive}$ behaviors in an acute arthritis model in rats. J Pharmacol Exp Ther 290: 214-219.
Lucke A, Musshoff U, Kohling R, Osterfeld M, Mayer T, Wolf P et al (1998). Gabapentin potentiation of the antiepileptic efficacy of vigabatrin in an in vitro model of epilepsy. $\mathrm{Br} J$ Pharmacol 124: $370-376$.

Luszczki JJ, Borowicz KK, Swiader M, Czuczwar SJ (2003a). Interactions between oxcarbazepine and conventional antiepileptic drugs in the maximal electroshock test in mice: an isobolographic analysis. Epilepsia 44: 489-499.

Luszczki JJ, Swiader M, Czuczwar M, Kis J, Czuczwar SJ (2003b). Interactions of tiagabine with some antiepileptics in the maximal electroshock in mice. Pharmacol Biochem Behav 75: 319-327.

Macdonald RL, Greenfield LJ (1997). Mechanisms of action of new antiepileptic drugs. Curr Opin Neurol 10: 121-128.

Meador KJ, Loring DW, Ray PG, Murro AM, King DW, Nichols ME et al (1999). Differential cognitive effects of carbamazepine and gabapentin. Epilepsia 40: 1279-1285.

Mortimore C, Trimble M, Emmers E (1998). Effects of gabapentin on cognition and quality of life in patients with epilepsy. Seizure 7: 359-364.

Murphy K, Delanty N (2000). Primary generalized epilepsies. Curr Treat Options Neurol 2: 527-542.

Nair DR, Najm I, Bulacio J, Luders H (2001). Painful auras in focal epilepsy. Neurology 57: 700-702.

Nielsen EB, Suzdak PD, Anderson KE, Knutsen LJ, Sonnewald U, Braestrup C (1991). Characterization of tiagabine (NO-328), a new potent and selective GABA uptake inhibitor. Eur $J$ Pharmacol 196: 257-266.

Novak V, Kanard R, Kissel JT, Mendell JR (2001). Treatment of painful sensory neuropathy with tiagabine: a pilot study. Clin Auton Res 11: 357-361.

Ojemann LM, Friel PN, Ojemann GA (1988). Gabapentin concentrations in human brain. Epilepsia 29: 694.

Olsen RW, Avoli M (1997). GABA and epileptogenesis. Progress in epilepsy research. Epilepsia 38: 399-407.

Parada-Turska J, Turski WA (1990). Excitatory amino acid antagonists and memory: effect of drugs acting at $N$-methyl-Daspartate receptors in learning and memory tasks. Neuropharmacology 29: 1111-1116.

Pellock JM (2001). Tiagabine (gabitril) experience in children. Epilepsia 42(Suppl 3): 49-51.

Perucca E (1995). Pharmacological principles as a basis for polytherapy. Acta Neurol Scand 162(Suppl): 31-34.

Perucca E (1997). Pharmacologic advantages of antiepileptic drug monotherapy. Epilepsia 38(Suppl 5): S6-S8.

Perucca E (2002). Overtreatment in epilepsy: adverse consequences and mechanisms. Epilepsy Res 52: 25-33.

Perucca E, Gram L, Avanzini G, Dulac O (1998). Antiepileptic drugs as a cause of worsening seizures. Epilepsia 39: 5-17.

Rambeck B, Specht U, Wolf P (1996). Pharmacokinetic interactions of the new antiepileptic drugs. Clin Pharmacokinet 31: 309-324.

Reynolds EH, Shorvon SD (1981). Single drug or combination therapy for epilepsy? Drugs 21: 374-382.

Rice AS, Maton S, Postherpetic Neuralgia Study Group (2001). Gabapentin in postherpetic neuralgia: a randomised, double blind, placebo controlled study. Pain 94: 215-224.

Richens A, Chadwick DW, Duncan JS, Dam M, Gram L, Mikkelsen $M$ et al (1995). Adjunctive treatment of partial seizures with tiagabine: a placebo-controlled trial. Epilepsy Res 21: 37-42.

Rogawski MA, Porter RJ (1990). Antiepileptic drugs: pharmacological mechanisms and clinical efficacy with consideration of promising developmental stage compounds. Pharmacol Rev 42: $223-286$.

Rowbotham M, Harden N, Stacey B, Bernstein P, Magnus-Miller L (1998). Gabapentin for the treatment of postherpetic neuralgia: a randomized controlled trial. JAMA 280: 1837-1842.

Rusy LM, Troshynski TJ, Weisman SJ (2001). Gabapentin in phantom limb pain management in children and young adults: report of seven cases. J Pain Symptom Manage 21: 78-82. 
Sachdeo RC, Leroy RF, Krauss GL, Drake ME, Green PM, Leppik IE et al (1997). Tiagabine therapy for complex partial seizures: a dose-frequency study. Arch Neurol 54: 595-601.

Savoldi F, Tartara A, Manni R, Maurelli M (1984). Headache and epilepsy: two autonomous entities? Cephalalgia 4: 39-44.

Schachter SC (1995). Tiagabine monotherapy in the treatment of partial epilepsy. Epilepsia 36(Suppl 6): S2-S6.

Schapel GJ, Chadwick D (1996). Tiagabine and non-convulsive status epilepticus. Seizure 5: 153-156.

Schmidt D (1996). Modern management of epilepsy: rational polytherapy. Baillieres Clin Neurol 5: 757-763.

Schmidt D (2002). Strategies to prevent overtreatment with antiepileptic drugs in patients with epilepsy. Epilepsy Res 52: 61-69.

Schmidt D, Elger C, Holmes GL (2002). Pharmacological overtreatment in epilepsy. Mechanisms and management. Epilepsy Res 52: 3-14.

Schmitt U, Hiemke C (2002). Tiagabine, a $\gamma$-amino-butyric acid transporter inhibitor impairs spatial learning of rats in the Morris water-maze. Behav Brain Res 133: 391-394.

Serpell MG, Neuropathic Pain Study Group (2002). Gabapentin in neuropathic pain syndromes: a randomised, double-blind, placebo-controlled trial. Pain 99: 557-566.

Shimoyama N, Shimoyama M, Davis AM, Inturrisi CE, Elliott KJ (1997). Spinal gabapentin is antinociceptive in the rat formalin test. Neurosci Lett 222: 65-67.

Shinnar S, Berg AT, Treiman DM, Hauser WA, Hesdorffer DC, Sackellares JC et al (2001). Status epilepticus and tiagabine therapy: review of safety data and epidemiologic comparisons. Epilepsia 42: 372-379.

Snead OC (1992). Evidence for GABAB-mediated mechanisms in experimental generalized absence seizures. Eur J Pharmacol 213: 343-349.
Stefani A, Spadoni F, Giacomini P, Lavaroni F, Bernardi G (2001). The effects of gabapentin on different ligand- and voltage-gated currents in isolated cortical neurons. Epilepsy Res 43: 239-248.

Surges R, Freiman TM, Feuerstein TJ (2003). Gabapcntin increases the hyperpolarization-activated cation current $1 \mathrm{~h}$ in rat CA1 pyramidal cells. Epilepsia 44: 150-156.

Tallarida RJ (1992). Statistical analysis of drug combinations for synergism. Pain 49: 93-97.

Tallarida RJ (2002). The interaction index: a measure of drug synergism. Pain 98: 163-168.

Tallarida RJ, Stone DJ, Raffa RB (1997). Efficient designs for studying synergistic drug combinations. Life Sci 61: PL417-PL425.

Taylor CP, Gee NS, Su TZ, Kocsis JD, Welty DF, Brown JP, Dooley DJ, Boden P, Singh L (1998). A summary of mechanistic hypotheses of gabapentin pharmacology. Epilepsy Res 29: 233-249.

Uthman BM, Rowan AJ, Ahmann NP, Leppik IE, Schachter SC, Sommerville KW et al (1998). Tiagabine for complex partial seizures. Arch Neurol 55: 56-62.

Venault P, Chapouthier G, de Carvalho LP, Simiand J, Morre M, Dodd RH et al (1986). Benzodiazepines impair and betacarbolines enhance performance in learning and memory tasks. Nature 321: 864-866.

White HS (1997). Clinical significance of animal seizure. Models and mechanism of action studies of potential antiepileptic drugs. Epilepsia 38(Suppl 1): S9-S17.

White HS (1999). Comparative anticonvulsant and mechanistic profile of the established and newer antiepileptic drugs. Epilepsia 40(Suppl 5): S2-S10.

Wong ICK, Chadwick DW, Fenwick PB, Mawer GE, Sander JWAS (1999). The long-term use of gabapentin, lamotrigine, and vigabatrin in patients with chronic epilepsy. Epilepsia 40: 1439-1445. 